\title{
What do chronic obstructive pulmonary disease patients die from? A multiple cause coding analysis
}

\author{
A.L. Hansell*, J.A. Walk\#, J.B. Soriano
}

What do chronic obstructive pulmonary disease patients die from? A multiple cause coding analysis. A.L. Hansell, J.A. Walk, J.B. Soriano. (C) ERS Journals Ltd 2003. ABSTRACT: Information on obstructive lung disease (OLD) deaths is generally derived from the underlying cause of death on the death certificate. This neglects information on other conditions mentioned and may underestimate the burden of disease.

Descriptive analyses of all conditions mentioned on the death certificate for all decedents where OLD (chronic obstructive pulmonary disease or asthma) was mentioned as a contributing cause of death were conducted for England and Wales for 1993-1999.

OLD was mentioned in 312,664 or $8.0 \%$ of all deaths. OLD comprised the underlying cause of death in $59.8 \%$ of deaths with any mention of OLD. Where OLD was not the underlying cause of death, the leading causes by the International Classification of Disease version 9 chapter were diseases of the circulatory system, neoplasms, and non-OLD diseases of the respiratory system. The top single causes were acute myocardial infarction, other ischaemic heart disease, and lung cancer.

The current analysis confirms that using the underlying cause of death underestimates the contribution of obstructive lung disease to mortality in England and Wales, in contrast to myocardial infarction where underlying cause of death captures most $(94 \%)$ mentions on the death certificate.

Eur Respir J 2003; 22: 809-814.
*Dept Epidemiology and Public Health, Imperial College London, London, UK, ${ }^{\text {\#S School of }}$ Public Health, University of Illinois at Chicago, Chicago, IL, USA, "Worldwide Epidemiology GlaxoSmithKline, Greenford, Middlesex and Health Promotion Research Unit, London School of Hygiene and Tropical Medicine, London, UK.

Correspondence: A. Hansell, Dept Epidemiology and Public Health, Imperial College London, St Mary's Campus, Norfolk Place, London, W2 1PG, UK.

Fax: 442074025253

E-mail: a.hansell@imperial.ac.uk

Keywords: Asthma, cause of death, death certificates, epidemiology, obstructive lung diseases

Received: March 202003

Accepted after revision: June 292003

A. Hansell was funded by a Wellcome Trust Research Fellowship in Clinical Epidemiology.
Chronic obstructive pulmonary disease (COPD) is a condition with significant morbidity and mortality and was estimated as the third leading cause of mortality worldwide in 1990 [1] and fourth leading cause of death in the USA in 1996 [2]. Work in the USA [3] has suggested that using underlying cause of death as an indicator of the health burden from severe COPD may dramatically underestimate the impact of the disease, with nonrespiratory causes accounting for $>50 \%$ of the underlying causes of death in COPD patients in the USA [3]. Most studies on the mechanisms and causes of death in COPD have been conducted on small groups of patients [4]. One of the largest such studies involved 215 decedents with COPD and on long-term oxygen therapy. This found that the major causes of death were acute-on-chronic respiratory failure, heart failure, pulmonary infection, pulmonary embolism, cardiac arrhythmia and lung cancer [5]. Much less is known of the circumstances of death and the specific causes of death of COPD patients in the community [4].

Data on all conditions mentioned on the death certificate in England and Wales became available electronically from 1993 [6]. This study aimed to quantify the extent to which obstructive lung disease (OLD) made a significant contribution to the death in the opinion of the certifying physician by examining the extent to which OLD was mentioned anywhere on the death certificate. The study also aimed to better characterise the specific causes of death in OLD patients in England and Wales, where OLD was mentioned on the death certificate but not the underlying cause.

\begin{abstract}
Methods
Mortality and population statistics for England and Wales in 1993-1999 were obtained from the Office for National Statistics. The medical certificate of cause of death in England and Wales is in the format recommended by the World Health Organisation (WHO), with a part I and part II. Part I has three lines (Ia, Ib and Ic) relating to the immediate cause of death (Ia) and going back through the sequence leading directly to the death in Ib and Ic. Part II is for other conditions that contributed to the death but were not part of the direct causal sequence [6]. The underlying cause of death, chosen by coding rules, is generally the condition entered in the lowest completed line of part I.

All conditions listed on death certificates were obtained for 1993-1999, where there was at least one mention of OLD (COPD or asthma, International Classification of Disease version 9 (ICD-9) codes 490-493, 496) on the certificate. Asthma codes were included because of the difficulty in distinguishing between the two conditions, particularly in later life [7].

Descriptive analyses were conducted for the multiple cause data for 1993-1999, including a determination of the causes of deaths for decedents where OLD was mentioned on the death certificate, but where OLD was not the underlying cause of death. Time trends used rates directly age-standardised to the population in 1999. A Chi-squared test for trend was used to examine for statistically significant linear trends. Confidence
\end{abstract}


Table 1.-Numbers and percentages of deaths in England and Wales 1993-1999 where obstructive lung disease (OLD) or asthma is mentioned anywhere on the death certificate by age group

\begin{tabular}{|c|c|c|c|c|}
\hline \multirow[t]{2}{*}{ Age yrs } & \multirow[t]{2}{*}{ All deaths $n$} & \multirow{2}{*}{$\begin{array}{c}\text { Deaths with OLD mentioned } \\
\text { n ( } \% \text { all deaths })\end{array}$} & \multicolumn{2}{|c|}{ Deaths with asthma mentioned } \\
\hline & & & n ( $\%$ all deaths $)$ & $\%$ of OLD mentioned \\
\hline$<1$ & 27349 & $56(0.20)$ & $4(0.01)$ & 7.1 \\
\hline $1-14$ & 11841 & $250(2.11)$ & $182(1.54)$ & 72.8 \\
\hline $15-24$ & 22674 & $386(1.70)$ & $332(1.46)$ & 86.0 \\
\hline $25-34$ & 40179 & $510(1.27)$ & $397(0.99)$ & 77.8 \\
\hline $35-44$ & 66609 & $1025(1.54)$ & $615(0.92)$ & 60.0 \\
\hline $45-54$ & 156356 & $4926(3.15)$ & $1313(0.84)$ & 26.7 \\
\hline $55-64$ & 342858 & $23414(6.83)$ & $2762(0.81)$ & 11.8 \\
\hline $65-74$ & 852221 & 91763 (10.77) & $5390(0.63)$ & 5.9 \\
\hline $75-84$ & 1309155 & $128856(9.84)$ & $6587(0.50)$ & 5.1 \\
\hline $85+$ & 1098731 & $61478(5.6)$ & $3628(0.33)$ & 5.9 \\
\hline Total & 3927973 & 312664 (7.96) & $21210(0.54)$ & 6.8 \\
\hline
\end{tabular}

intervals were not presented for rates because a $100 \%$ sample was used.

\section{Results}

Over the 7-yr period 1993-1999 OLD was mentioned anywhere on the death certificate for 312,664 decedents and the underlying cause of death was coded to an OLD in $59.8 \%$ $(186,852)$ of cases. OLD comprised the underlying cause of death for just under $5 \%$ of all deaths and was mentioned anywhere on the death certificate (including underlying cause of death) for $8 \%$ of all deaths (table 1 ). These proportions varied by sex. OLD was the underlying cause of death in $5.7 \%$ of male death certificates and $3.8 \%$ of female death certificates and it was mentioned on $9.9 \%$ of male death certificates and $6.2 \%$ of female death certificates.

Rates for OLD mentioned anywhere on the death certificate and as underlying cause of death increased with age, with highest rates in the oldest age-groups and lowest in the youngest. The age-specific rates for OLD as underlying cause of death for 1993-1999 combined ranged from 0.37 per 100,000 for males and 0.23 per 100,000 for females aged
$0-9$ yrs to 1,324 per 100,000 for males and 359 per 100,000 for females aged $\geqslant 90$ yrs.

The commonest code used for OLD in 1993-1999 was chronic airways obstruction, not elsewhere classified (ICD-9 496 , comprising $\sim 80 \%$ of codes where an OLD was the underlying cause of death or where OLD was mentioned anywhere on the death certificate (table 2). The next most common code was chronic bronchitis (ICD-9 491) comprising $\sim 10 \%$ of male and $7 \%$ of female codes. Emphysema (ICD-9 492) and bronchitis unspecified (ICD-9 490) were less commonly used and appeared more frequently as a mention on the death certificate than as the underlying cause of death (table 2). Bronchitis codes (ICD-9 490-491) and COPD unspecified (ICD-9 496) were more commonly used in the oldest age groups (fig. 1).

Asthma accounted for $\sim 6.8 \%$ of deaths with any mention of OLD and $0.5 \%$ of all deaths in England and Wales for 1993-1999. The use of asthma codes varied by age and sex: asthma was mentioned more often in female death certificates $(10.1 \%$ of female decedents with any mention of OLD versus $4.6 \%$ of males) and in younger age groups. Asthma was the commonest OLD reported on death certificates for those aged 1-44 yrs (table 1, fig. 1) and became less common with increasing age.

Table 2. - Numbers of deaths (\% of decedents) in England and Wales 1993-1999 by International Classification of Disease version 9 (ICD-9) code where obstructive lung disease (OLD) was the underlying cause of death or mentioned anywhere on the death certificate

\begin{tabular}{|c|c|c|c|c|}
\hline ICD-9 code & Description & Male & Female & All \\
\hline \multicolumn{5}{|l|}{ Underlying cause } \\
\hline 490 & Bronchitis, unspecified & $613(0.6 \%)$ & $879(1.1 \%)$ & $1492(0.8 \%)$ \\
\hline 491 & Chronic bronchitis & $10612(9.8 \%)$ & $5855(7.5 \%)$ & $16497(8.8 \%)$ \\
\hline 492 & Emphysema & $8806(8.1 \%)$ & $4060(5.2 \%)$ & $12866(6.9 \%)$ \\
\hline 493 & Asthma & $3879(3.6 \%)$ & $6297(8.1 \%)$ & $10176(5.4 \%)$ \\
\hline 496 & $\begin{array}{l}\text { Chronic airways obstruction not } \\
\text { elsewhere classified }\end{array}$ & $84788(78.0 \%)$ & $61063(78.1 \%)$ & $145851(78.1 \%)$ \\
\hline $490-3,496$ & Total OLD & $108698(100 \%)$ & $78154(100 \%)$ & $186852(100 \%)$ \\
\hline \multicolumn{5}{|c|}{ Any mention on death certificate } \\
\hline 490 & Bronchitis, unspecified & $2413(1.3 \%)$ & $2401(1.8 \%)$ & $4814(1.5 \%)$ \\
\hline 491 & Chronic bronchitis & $17907(9.6 \%)$ & $9134(7.2 \%)$ & $27041(8.6 \%)$ \\
\hline 492 & Emphysema & $27681(14.8 \%)$ & $10377(8.2 \%)$ & $38058(12.2 \%)$ \\
\hline 493 & Asthma & $8501(4.6 \%)$ & $12709(10.1 \%)$ & $21210(6.8 \%)$ \\
\hline 496 & $\begin{array}{l}\text { Chronic airways obstruction, not } \\
\text { elsewhere classified }\end{array}$ & $146072(78.2 \%)$ & $98114(77.9 \%)$ & $244186(78.1 \%)$ \\
\hline 490-3, 496 (decedents) & $\begin{array}{l}\text { Number of decedents with any } \\
\text { mention of OLD }\end{array}$ & $186681(100 \%)$ & $125994(100 \%)$ & $312675(100 \%)$ \\
\hline 490-3, 496 (mentions) & Number of mentions of OLD & $202574(108.5 \%)$ & $132735(105.4 \%)$ & $335309(107.2 \%)$ \\
\hline
\end{tabular}



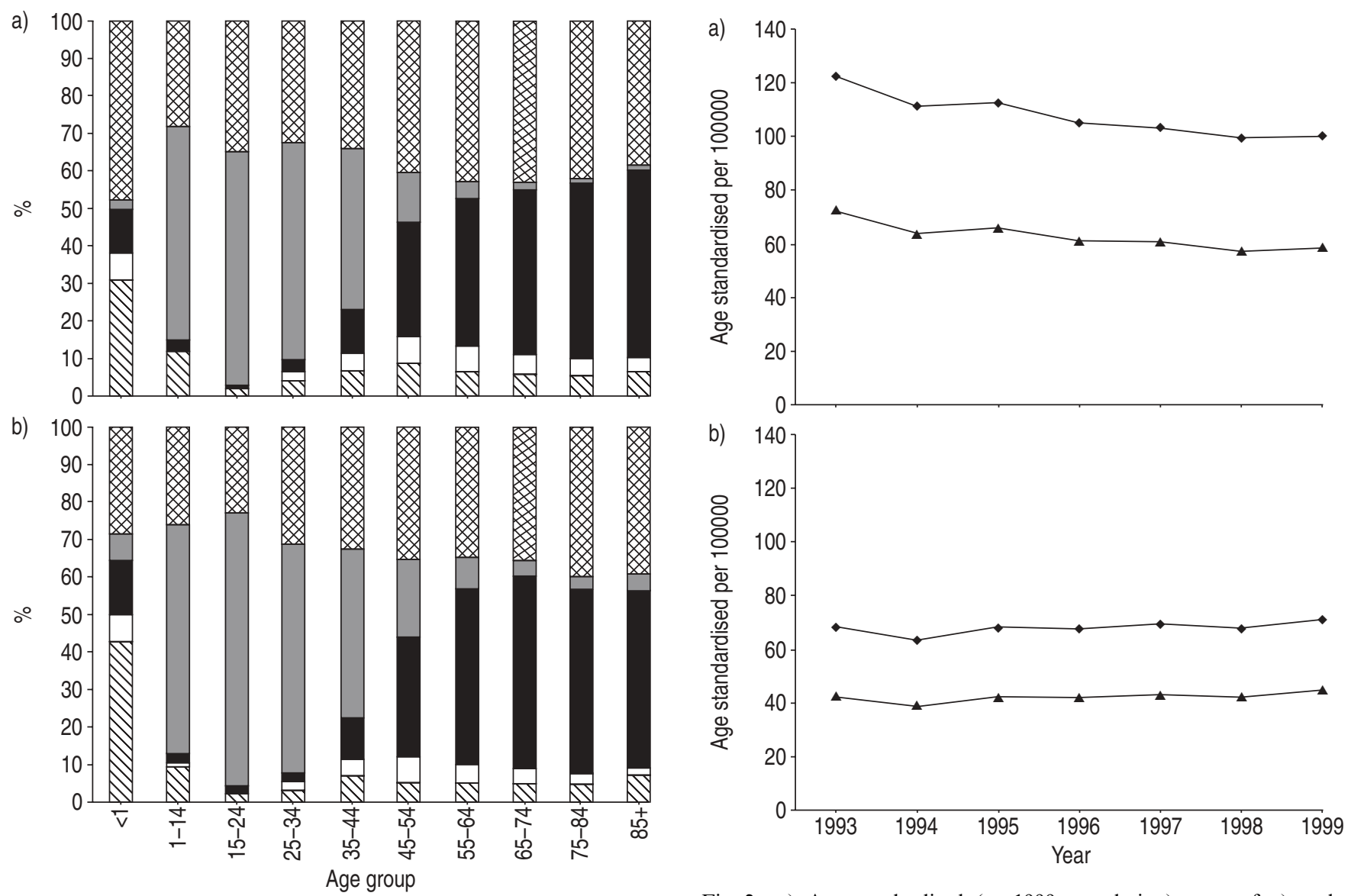

Fig. 1.-a) Proportion of male deaths with any mention of obstructive lung disease where the underlying cause of death was coded to bronchitis (International Classification of Disease version 9 (ICD-9) 490, 491), emphysema (ICD-9 492), chronic obstructive pulmonary disease (COPD) (ICD-9 496), asthma (ICD-9 493) or other for 19931999 by age. b) Proportion of female deaths with any mention of obstructive lung disease where the underlying cause of death was coded to bronchitis (ICD-9 490, 491), emphysema (ICD-9 492), COPD (ICD-9 496), asthma (ICD-9 493) or other for 1993-1999 by age. $\mathbb{\mathbb { }}$ : bronchitis; $\square$ : emphysema; $\mathbf{\square}$ : COPD unspecified; $\square$ : asthma; : other.

\section{Multiple mentions of $O L D$ on the death certificate}

Of death certificates where there was any mention of OLD from 1993-1999, a total of 15,295 (8.5\%) males and 6,864 (5.4\%) females had more than one OLD mentioned (usually two). The commonest combinations were chronic bronchitis (ICD-9 491) with emphysema (ICD-9 492), followed by emphysema (ICD-9 492) with chronic airways obstruction (ICD-9 496) then asthma (ICD-9 493) with chronic airways obstruction (ICD-9 496).

\section{Time trends 1993-1999}

Trends in deaths with any mention of OLD on the death certificate paralleled those where OLD was the underlying cause of death (fig. 2) and Chi-squared tests suggested these were statistically significant linear trends $(p<0.001)$. The proportion of all death certificates with any mention of OLD decreased in males from $10.4 \%$ in 1993 to $9.9 \%$ in 1999 and increased in females from $6.0 \%$ in 1993 to $6.5 \%$ in 1999 . Since mentions of COPD comprised the majority of OLD mentions, the trends for COPD closely paralleled those for

Fig. 2.-a) Age-standardised (to 1999 population) rates of a) male and b) female deaths per 100,000 in England and Wales where obstructive lung disease (OLD) is cited as the underlying cause of death and where OLD is mentioned anywhere on the death certificate. $\diamond$ : OLD any mention; $\boldsymbol{\Delta}$ : OLD as underlying cause.

OLD. However, age-standardised rates for any mention of asthma fell faster than those for COPD and the rates for asthma as an underlying cause of death fell faster than those for any mention of asthma (table 3).

Table 3. - Age-standardised (to 1999 population) mortality rates per 100,000 for asthma (ICD-9 493) or chronic obstructive pulmonary disease (COPD) (ICD-9 490-2, 496) mentioned anywhere on the death certificate or as underlying cause of death

\begin{tabular}{|c|c|c|c|c|}
\hline Year & $\begin{array}{c}\text { Asthma any } \\
\text { mention }\end{array}$ & $\begin{array}{l}\text { Asthma as } \\
\text { underlying } \\
\text { cause of death }\end{array}$ & $\begin{array}{l}\text { COPD any } \\
\text { mention }\end{array}$ & $\begin{array}{c}\text { COPD as } \\
\text { underlying } \\
\text { cause of death }\end{array}$ \\
\hline
\end{tabular}

\begin{tabular}{ccccc}
\hline $\begin{array}{c}\text { Male } \\
1993\end{array}$ & 9.7 & 4.6 & 247.7 & 144.7 \\
1994 & 9.3 & 3.9 & 224.0 & 127.3 \\
1995 & 9.3 & 3.4 & 227.0 & 132.7 \\
1996 & 8.3 & 3.2 & 211.2 & 122.8 \\
1997 & 7.9 & 3.4 & 206.6 & 121.2 \\
1998 & 7.3 & 3.1 & 199.9 & 114.6 \\
1999 & 7.0 & 2.9 & 201.9 & 117.4 \\
Female & & & & \\
1993 & 10.6 & 5.4 & 89.1 & 55.1 \\
1994 & 9.5 & 4.5 & 83.8 & 51.4 \\
1995 & 9.5 & 4.6 & 91.5 & 56.6 \\
1996 & 9.0 & 4.3 & 91.1 & 56.7 \\
1997 & 9.5 & 4.5 & 93.5 & 58.3 \\
1998 & 8.8 & 4.2 & 92.3 & 57.4 \\
1999 & 8.7 & 4.2 & 96.2 & 60.9 \\
\hline
\end{tabular}


Characterisation of deaths 1993-1999 by ICD chapter and by single cause where OLD was mentioned but not the underlying cause of death

Examination of the underlying cause of death for decedents where OLD was mentioned but not the underlying cause by ICD chapter showed that the most frequent causes of death for all years and for both males and females were diseases of the circulatory system, followed by neoplasms and diseases of the respiratory system (table 4). A disease of the circulatory system (ICD-9 Chapter 7) was listed as the underlying cause of death in approximately a quarter of all deaths that had an OLD mentioned on their death certificate, with a further $8 \%$ of males and $5 \%$ of females having a neoplasm (ICD-9 Chapter 2) and $4 \%$ of male and female deaths with a respiratory system disease (excluding OLD) as the underlying cause of death during the study period.

Analysis by three-digit ICD-9 code (table 4) showed that the commonest causes of death where OLD was mentioned but not the underlying cause were ischaemic heart disease, followed by lung cancer and bronchopneumonia. These rankings were fairly stable over 1993-1999, but "Acute, but ill-defined cerbrovascular disease" (ICD-9 436), a code used for stroke was one of the top five causes in 1993 only for both sexes. Heart failure (ICD-9 428) also featured in the top five causes of death (with different rankings for males and females) and this may have included some cases of cor pulmonale, if not clearly specified by the certifying doctor. The specific code for chronic cor pulmonale (ICD-9 416.9) was the 19th most common underlying cause of death in females and 27th most common in males in 1993-1999 in this group of decedents and became progressively less common over time, falling from 94 cases in 1993 to 44 cases in 1999 in males and 62 to 34 cases in females.

The most frequent four-digit codes for both males and females were 410.0, acute myocardial infarction and 414.9, other forms of chronic ischaemic heart disease, unspecified (table 4). The top five four-digit ICD causes of death generally occurred in the same order in each year. The percentage of cases with "other forms of chronic ischaemic heart disease" as the underlying cause of death remained fairly stable over the study period, but the percentage attributed to acute myocardial infarction fell (from $9.5 \%$ in 1993 to $6.7 \%$ in 1999 in males and $8.1 \%$ in 1993 to $5.1 \%$ in 1999 in females).

\section{Discussion}

This multiple cause analysis of death certificates in England and Wales for 1993-1999 found that OLD was mentioned on $8.0 \%$ of death certificates and that in $59.8 \%$ of these, the underlying cause of death was attributed to OLD. Two similar multiple cause analyses of death certificates have been conducted in the USA. MANNINO et al. [3] examined mortality trends 1979-1993 and found that OLD was mentioned on $8.2 \%$ of all decedents, while the National Mortality Followback Survey in 1993 found that COPD was mentioned in $10.6 \%$ of decedents [8]. Both these studies found a much lower percentage for the underlying cause of death: $43.3 \%$ of deaths with any mention of OLD in the 1979-1993 study [3] and $42.2 \%$ for deaths with any mention of COPD in the 1993 study [8]. One likely explanation for this is certification differences between the USA and England and Wales. Co-morbidities are better recorded in the USA than in UK hospitalisation data [9], and this may extend to death certification. Also inadequacies in training of doctors in England and Wales with relation to death certification have been documented [6]. An alternative and speculative explanation may relate to severity of OLD. If there were similar underlying prevalences in the two countries, but OLD was more severe or less aggressively treated during the study period in the UK one might expect a greater percentage of

Table 4.-Commonest underlying causes of death for decedents where obstructive lung disease (OLD) was mentioned on the death certificate but not the underlying cause of death, 1993-1999

\begin{tabular}{|c|c|c|c|}
\hline \multicolumn{2}{|l|}{ Male } & \multicolumn{2}{|l|}{ Female } \\
\hline ICD-9 classification & $\begin{array}{l}\mathrm{n}(\% \text { OLD } \\
\text { mentions })\end{array}$ & ICD-9 classification & $\begin{array}{l}\mathrm{n}(\% \text { OLD } \\
\text { mentions) }\end{array}$ \\
\hline ICD-9 chapter & & ICD-9 chapter & \\
\hline 7-Circulatory System & $47849(25.6 \%)$ & 7-Circulatory System & $30145(23.9 \%)$ \\
\hline 2-Neoplasms & $14557(7.8 \%)$ & 2-Neoplasms & $6894(5.5 \%)$ \\
\hline 8-Respiratory System (excluding 490-493.9, 496) & $7326(3.9 \%)$ & 8-Respiratory System (excluding 490-493.9, 496) & $5066(4.0 \%)$ \\
\hline ICD-9 three-digit code & & ICD-9 three-digit code & \\
\hline $\begin{array}{l}414 \text { Other forms of chronic ischaemic heart } \\
\text { disease }\end{array}$ & $18246(9.8 \%)$ & $\begin{array}{l}414 \text { Other forms of chronic ischaemic heart } \\
\text { disease }\end{array}$ & $10288(8.2 \%)$ \\
\hline 410 Acute myocardial infarction & $15269(8.2 \%)$ & 410 Acute myocardial infarction & $8357(6.6 \%)$ \\
\hline $\begin{array}{l}162 \text { Malignant neoplasm of trachea, bronchus } \\
\text { and lung }\end{array}$ & $6824(3.7 \%)$ & 428 Heart failure & $3119(2.5 \%)$ \\
\hline 485 Bronchopneumonia, organism unspecified & $3534(1.9 \%)$ & $\begin{array}{l}162 \text { Malignant neoplasm of trachea, bronchus } \\
\text { and lung }\end{array}$ & $3108(2.5 \%)$ \\
\hline 428 Heart failure & $3037(1.6 \%)$ & 485 Bronchopneumonia, organism unspecified & $2961(2.4 \%)$ \\
\hline ICD-9 four-digit code & & ICD-9 four-digit code & \\
\hline 4100 Acute myocardial infarction & $15269(8.2 \%)$ & $\begin{array}{l}4149 \text { Other forms of ischaemic heart disease; } \\
\text { unspecified }\end{array}$ & $8429(6.7 \%)$ \\
\hline $\begin{array}{l}4149 \text { Other forms of ischaemic heart disease; } \\
\text { unspecified }\end{array}$ & $13530(7.2 \%)$ & 4100 Acute myocardial infarction & $8357(6.6 \%)$ \\
\hline $\begin{array}{l}1629 \text { Malignant neoplasm of trachea, bronchus, } \\
\text { and lung; bronchus and lung, unspecified }\end{array}$ & $6600(3.5 \%)$ & $\begin{array}{l}1629 \text { Malignant neoplasm of trachea, bronchus, } \\
\text { and lung; bronchus and lung, unspecified }\end{array}$ & $3014(2.4 \%)$ \\
\hline $\begin{array}{l}4140 \text { Other forms of ischaemic heart disease; } \\
\text { coronary atherosclerosis }\end{array}$ & $4257(2.3 \%)$ & 4850 Bronchopneumonia, organism unspecified & $2961(2.4 \%)$ \\
\hline 4850 Bronchopneumonia; organism unspecified & $3068(1.6 \%)$ & 4360 Acute but ill-defined cerebrovascular disease $\mathrm{e}^{\#}$ & $2135(1.7 \%)$ \\
\hline
\end{tabular}

Data are presented as n (\% OLD mentions). ICD-9: International Classification of Disease version 9. ${ }^{*}$ : includes stroke. 
decedents with OLD as underlying cause of death. Treatment differences are described: for example, low intubation rates and higher mortality in COPD patients compared with the USA and some European countries were noted [10] in a UK study of noninvasive ventilation conducted in 1996-1998, while noninvasive ventilation was not available in half the hospitals in the UK in a 1997 survey [11]. An international population survey conducted in 2000 [12] did indeed find similar prevalences of COPD in both countries. OLD was also mentioned on a similar percentage of all death certificates in this analysis as in the USA analyses [3, 8] which could indicate similar prevalence of more severe disease. However, both survey and death certificates relied on doctor-diagnosed disease and this explanation would not hold if doctors were more willing to diagnose or detect OLD in the USA.

Underlying cause of death may be a reasonable measure of certified deaths for some conditions such as myocardial infarction: underlying cause comprised $93.6 \%$ of any mentions of myocardial infarction on the death certificate in a recent English study [13]. However, the present analysis demonstrated that use of underlying cause of death may substantially underestimate the contribution of OLD to mortality in England and Wales. Despite this, time trends for OLD as an underlying cause of death should be similar to those for deaths to which OLD has contributed.

Not all patients with OLD in life will have OLD mentioned on the death certificate, for example, because it did not contribute to the final illness or because of poor recording of comorbidities. The Tucson Epidemiologic Study of Airways Obstructive Diseases [14] suggested that patients with spirometric evidence of airways disease in life only had airways disease reported on the death certificate in 13\% (9 of 71 cases), but that the percentage was much higher $(77 \%)$ in cases with moderate-to-severe disease (patients with forced expiratory volume in one second $\%<50$ ). A 22-yr follow-up of 5,542 adults in the first National Health and Nutrition Examination Survey (NHANES I) found that $47.7 \%$ of patients with severe COPD at baseline had COPD listed on the death certificate and $23.1 \%$ had COPD as the underlying cause of death [15]. However, COPD diagnosis was based at spirometry at baseline only, percentages would almost certainly have been higher if information on COPD progression during follow-up had been available.

Ischaemic heart disease, lung cancer and bronchopneumonia (table 3 ) formed the major underlying causes of death in England and Wales, where OLD was mentioned on the certificate but not the immediate cause of death. These findings are broadly in agreement with those in the Tucson study [14]: where airways obstructive disease was mentioned on the death certificate ( 86 decedents), the underlying cause of death was cardiovascular (ICD-9 410.9-414.9) in $42 \%$ of cases, other pulmonary diseases (ICD-9 485-6, 512-516 and 799.1 ) in $26 \%$ and malignancy (ICD-9 153.9-197.7) in $9 \%$. Minor differences may relate to the time periods covered (1972-1986 for the Tucson study) and the smaller numbers involved for the Tucson study. ZIELINSKI et al. [5] examined causes of deaths in 215 patients on long-term oxygen therapy in seven European countries. They found that the major causes of death were acute-on-chronic respiratory failure $(38 \%)$, cor pulmonale with oedema $(13 \%)$, pulmonary infection $(11 \%)$, pulmonary embolism $(10 \%)$, fatal arrhythmia $(8 \%)$ and lung cancer $(7 \%)$. While it is difficult to make direct comparisons as ICD coded (underlying) causes of death were not given, the European patients with severe COPD had higher proportions of death from cor pulmonale and from lung cancer than this British general population sample (table 3).

Mortality data for England and Wales are nearly 100\% complete and almost all registered deaths have been certified by a medical practitioner or coroner [6]. In 1993, automated coding for cause of death was introduced, incorporating software developed in the USA and applying the American interpretation of the WHO rules, which aids some international comparisons [6]. However, $<10 \%$ of deaths certified by doctors in England and Wales include information from a post mortem [6] and this may lead to some inaccuracies in the certified cause of death. Studies of death certificates suggest that a label of asthma may be preferentially applied to females with COPD and that some asthma deaths are recorded as COPD and vice versa $[16,17]$. Because of this and variations in physician preferences for the various COPD codes, the current authors chose to analyse OLD comprising all COPD and asthma codes. Other limitations of death certificate data are the lack of information on the severity of disease and risk factor information such as occupational exposures and cigarette smoking [3].

Few analyses on the validity of UK death certificates in OLD have been conducted in recent years. Two studies conducted within 10 yrs of the present analysis found reasonable agreement of death certificates with hospital and case notes. GUITE and BURNEY [18] convened an expert panel to review deaths in 1988-1992 occurring in a cohort of 2,382 patients previously hospitalised for asthma, to see if these might have been due to asthma. The panel identified 26 asthma deaths, of which $24(92 \%)$ were certified as asthma, two (8\%) had been attributed to COPD and two $(8 \%)$ to cardiovascular disease. SMYTH et al. [17] reviewed case notes of decedents in Northern Ireland in 1987 aged $<75$ yrs where asthma or COPD was mentioned anywhere on the death certificate. The panel found the same number of deaths where OLD was the underlying cause as had been certified to OLD, but these were differently distributed. Of the 174 deaths where OLD was certified the underlying cause of death, $125(72 \%)$ were confirmed as OLD. Of 176 deaths where OLD was mentioned but not the underlying cause, the panel considered that OLD should have been the underlying cause in $49(28 \%)$ of cases. It is unclear how relevant these finding are to the present analysis as coding was not computerised and the authors commented on the variable application of coding rules to determine the underlying cause of death by the registering officers.

In conclusion, this study aimed to better determine the epidemiology of deaths from obstructive lung disease in England and Wales. Underlying cause of death data are commonly used when looking at the burden of lung disease [19] but were found to substantially underestimate the number of deaths to which obstructive lung disease makes a contribution. Where obstructive lung disease was mentioned but not the underlying cause of death, the commonest causes were other smoking-related conditions such as heart disease and lung cancer. Formal medical record review of decedents is now needed to definitively determine the degree to which death certification underestimates the contribution of obstructive lung disease to mortality.

\section{References}

1. Murray CJL, Lopez AD. The Global Burden of Disease. Harvard, Harvard University Press, 1996.

2. Hurd S. The impact of COPD on lung health worldwide: epidemiology and incidence. Chest 2000; 117: Suppl. 1S-4S

3. Mannino DM, Brown C, Giovino GA. Obstructive lung disease deaths in the United States from 1979 through 1993. Am J Respir Crit Care Med 1997; 156: 814-818.

4. Zielinski J. Circumstances of death in chronic obstructive pulmonary disease. Proc - COPD Manag 1998; 53: 324-330.

5. Zielinski J, MacNee W, Wedzicha JA, et al. Causes of death 
in patients with COPD and chronic respiratory failure. Mon Arch Chest Dis 1997; 52: 43-47

6. Devis T, Rooney C. Death certification and the epidemiologist. Health Stat Quarterly 1999; 01(Spring): 25-33.

7. Hunt LW, Silverstein MD, Reed CE, O'Connell EJ, $\mathrm{O}^{\prime}$ Fallon WM, Yuginger JW. Accuracy of the death certificate in a population-based study of asthmatic patients. J Am Med Assoc 1993; 269: 1947-1952.

8. Meyer PA, Mannino DM, Redd SC, Olson DR. Characteristics of adults dying with COPD. Chest 2002; 122: 20032008.

9. McKee M, Coles J, James P. "Failure to rescue" as a measure of quality of hospital care: the limitations of secondary diagnosis coding in English hospital data. $J$ Publ Health Med 1999; 21: 453-458.

10. Plant PK, Owen JL, Parrott S, Elliott MW. Cost effectiveness of ward based non-invasive ventilation for acute exacerbations of chronic obstructive pulmonary disease: economic analysis of randomised controlled trial. $B M J$ 2003; 326: 956-960.

11. Doherty MJ, Greenstone MA. Survey of non invasive ventilation (NIPPV) in patients with acute exacerbation of chronic obstructive pulmonary disease (COPD) in the UK. Thorax 1998; 57: 192-211.

12. Rennard S, Decramer M, Calverley PMA, et al. Impact of COPD in North America and Europe in 2000: subjects perspective of Confronting COPD International Survey. Eur Respir J 2002; 20: 799-805.

13. Goldacre MJ, Roberts SE, Griffith M. Multiple-cause coding of death from myocardial infarction: population-based study of trends in death certificate data. J Publ Health Med 2003; 25: 69-71.

14. Camilli AE, Robbins DR, Lebowitz MD. Death certificate reporting of confirmed airways obstructive disease. $\mathrm{Am}$ J Epidemiol 1991; 133: 795-800.

15. Mannino DM, Buist AS, Petty TL, Enright PL, Redd SC. Lung function and mortality in the United States: data from the First National Health and Nutrition Examination Survey follow up study. Thorax 2003; 58: 388-393.

16. Jones K, Berrill WT, Bromly CL, Hendrick DJ. A confidential enquiry into certified asthma deaths in the North of England, 1994-96: influence of co-morbidity and diagnostic inaccuracy. Respir Med 1999; 93: 923-927.

17. Smyth ET, Wright SC, Evans AE, Sinnamon DG, MacMahon J. Death from airways obstruction: accuracy of certification in Northern Ireland. Thorax 1996; 51: 293-297.

18. Guite HF, Burney PGJ. Accuracy of recording of deaths from asthma in the UK: the false negative rate. Thorax 1996; 51: 924-928.

19. British Thoracic Society. The Burden of Lung Disease. A statistics report from the British Thoracic Society. London, British Thoracic Society, 2001. 